\title{
GARIMPANDO IDEIAS PARA A RECONSTRUÇÃO DO CÍRCULO HERMENÊUTICO E DO CÍRCULO DE CULTURA
}

Adilson Cristiano Habowski ${ }^{1}$

Daniel Felipe Jacobi ${ }^{2}$

Elaine Conte C $^{3}$

\section{1, INTRODUÇÃO}

Embora Hans-George Gadamer (1900-2002) e Paulo Freire (1921-1997) surgem como filósofos e críticos em diferentes contextos do mundo justificam e conservam lógicas e posturas que denotam grande similitude. Gadamer, mais voltado para a dimensão fenomenológica e ontológica, nos leva a refletir sobre o círculo hermenêutico, não enquanto um método fechado, mas como atitude filosófica aberta e necessária para a compreensão e interpretação. Por sua vez, Freire, no conceito de círculo de cultura, apresenta o entendimento de ser humano, de sistema educacional, assinalando a (co)existência e a cultura do diálogo para buscar a humanização, destacando a comunicação como uma possibilidade ontológica do ser mais, de libertação dos sujeitos. O conhecimento não é resultado de uma consciência subjetiva esclarecida, mas sim de uma tentativa de emancipação coletiva através do diálogo, em que cada sujeito coloca seus preconceitos, suas experiências, fazendo com que a construção do conhecimento reverta em uma aprendizagem cooperativa. Nesta abordagem, a realidade é entendida como uma construção social e tomada de consciência da própria historicidade, de sujeitos que interagem entre si e com o mundo (natureza, objetos), numa ação dialética, tornando possível compreender a capacidade de crítica da própria trajetória (GADAMER, 2006; FREIRE, 1982).

Seja no círculo hermenêutico ou no círculo de cultura, o diálogo surge como capacidade de mudar o mundo, já que é o ponto de partida para atingir novos horizontes e possibilidades de narrar e narrar-se. Assim, com esse estudo buscamos identificar os enlaces e as semelhanças entre Gadamer e Freire, tendo como fio condutor a vinculação do círculo hermenêutico e do círculo de

\footnotetext{
1 Mestrando em Educação na Universidade La Salle - UNILASALLE, Canoas/RS. Bolsista CAPES/PROSUC. Integrante do grupo de pesquisa NETE/CNPq. E-mail: adilsonhabowski@ hotmail.com

${ }^{2}$ Graduado em Teologia pela Universidade La Salle - UNILASALLE, Canoas/RS. Integrante do grupo de pesquisa NETE/CNPq. E-mail: danielfjacobi@hotmail.com

${ }^{3}$ Doutora em Educação (UFRGS). Professora do Programa de Pós-Graduação em Educação da Universidade La Salle UNILASALLE e líder do Núcleo de Estudos sobre Tecnologias na Educação - NETE/CNPq. E-mail: elaine.conte@unilasalle.edu.br
} 
cultura. Ancorados na perspectiva hermenêutica enquanto atitude metodológica, visamos promover uma fusão de horizontes para adentrar no universo interpretativo e buscar os sentidos dos discursos e dos textos produzidos pelos pensadores. Dentre todas as criações humanas, "a linguagem humana deve ser pensada como um processo vital particular e único, pelo fato de que no entendimento linguístico se torna manifesto o mundo", sendo o círculo dialógico um dos meios para a realização de entendimentos entre os interlocutores (GADAMER, 2005, p. 647). Daí que a dimensão hermenêutica provém da abertura à linguagem comum entre os sujeitos, que faz brotar novos sentidos para a dimensão política de dar voz ao outro, reavaliando o que é bom e correto na vida em comunidade e fazendo surgir novos textos, que são produtos da ação coletiva em processos circulares de cultura e na interdependência compreensiva do diálogo.

\section{O CÍRCULO HERMENÊUTICO ENQUANTO ESTRUTURA DIALÓGICA}

Hans-George Gadamer, filósofo alemão, teve papel marcante no desenvolvimento e aprimoramento da hermenêutica filosófica. Desde muito cedo esteve em contato com a filosofia ontológica, fenomenológica e hermenêutica de Martin Heidegger (1889-1976), herdando o entendimento da compreensão de ser-aí (ideia do Dasein, do ser jogado no mundo). Gadamer não somente dá continuidade ao raciocínio de Heidegger, mas aprimora esta perspectiva acentuando a ideia de que o ser que pode ser compreendido é linguagem. Neste contexto, o interessa ao estudo é o círculo de compreensão iniciado por Heidegger, que, ao chegar às mãos de Gadamer, ganha uma conotação hermenêutica.

Gadamer procura mostrar como o fato de Heidegger demonstrar a estrutura circular da compreensão - a partir da própria temporalidade da condição fática do homem - tem consequências para a hermenêutica das ciências do espírito. $\mathrm{O}$ círculo, na medida em que não é um círculo vicioso, pretende descrever o modo como a interpretação é realizada concretamente, onde o ponto de partida jamais é algo neutro. Gadamer exemplifica essa noção com a leitura de um texto: ao procurar compreender algo que lemos, sempre realizamos um "projetar" em relação ao sentido do todo, do mesmo modo que partimos das nossas concepções prévias que determinam a compreensão. (MISSAGGIA, 2012, p. 5).

Gadamer reconhece a hermenêutica como a base de qualquer atividade humana que busca o sentido compreensivo. Assim, no processo de compreensão linguística reconhecemos a existência de uma série de círculos hermenêuticos. Com base na obra Verdade e método, de Hans-Georg Gadamer, a perspectiva hermenêutica obtém uma caraterística universal, contribuindo para uma 
concepção de busca de sentido da totalidade do real, mas que se entende como um conhecimento sempre provisório e movente, que leva em questão a efetividade da consciência histórica. Compreender um texto é sempre um cogitar, um reapropriar-se, um projetar-se, pois no movimento de assimilação dos sentidos possíveis do ato de ler, devem-se levar em consideração as apropriações de quem o lê, e que, ao mesmo tempo, é preciso aperfeiçoar-se conforme o progresso das leituras, tornando-se uma constante revisão e intensificação para a busca de sentidos mais complexos e híbridos, próprios da dinâmica da vida. A experiência com o texto libera gestos desconhecidos, com avanços e recuos, oscilando no jogo linguístico da invenção e da modificação do leitor. Tudo isso depende da autonomia do sujeito em relação ao próprio exercício da leitura, ao outro, ao mundo, enfim, depende de uma transformação ativa das relações sociais estabelecidas.

O círculo hermenêutico compreende o todo a partir das partes (sujeito particular) e do sujeito particular a partir do todo. Neste movimento amplia-se o horizonte compreensivo que ocorre do todo para o particular e vice-versa, para aprofundar os sentidos em círculos concêntricos, com cada individualidade reconhecida com o todo. Conforme a perspectiva heideggeriana sobre o círculo hermenêutico, a compreensão das leituras situa-se no movimento que leva em conta o entendimento prévio (pré-compreensão subjetiva). A postura hermenêutica é anterior à lógica indutiva, que buscava encontrar a regularidade, legalidade e uniformidade nos fenômenos humanos por meio de um método, tentando reduzir o sujeito ao que mensura objetivamente a realidade, desconsiderando as dimensões subjetivas e intersubjetivas presentes nas relações, nos comportamentos e nos processos sociais (GADAMER, 2005). A hermenêutica transita na dinâmica da pergunta e da resposta entre a estranheza e a familiaridade da tradição, buscando esclarecer as incompreensões e possíveis distorções da comunicação em termos de patologias sociais, a fim de dar condições às diferentes manifestações e compreensões presentes na pluralidade da vida no mundo.

[...] uma consciência formada hermeneuticamente tem que se mostrar receptiva, desde o princípio, para a alteridade do texto. Mas essa receptividade não pressupõe nem 'neutralidade' com relação à coisa nem tampouco auto-anulamento, mas inclui a apropriação das próprias opiniões prévias e preconceitos, apropriação que se destaca destes. O que importa é dar-se conta das próprias antecipações, para que o próprio texto possa apresentar-se em sua alteridade e obtenha assim a possibilidade de confrontar sua verdade com as próprias opiniões prévias (GADAMER, 2002, p. 407).

Existe um entendimento de que quando nos perturbamos com um texto, influenciados pela nossa relação com o assunto, com expectativas de sentido e abertura à opinião do texto (do outro), 
desenvolvemos uma atitude hermenêutica de diálogo e intercomunicação. Isso não supõe neutralidade, pois são os preconceitos não percebidos que nos afastam e aproximam do legado da tradição. Conforme Gadamer, por influência do Iluminismo, o preconceito recebeu uma compreensão negativa, mas seu sentido representa um juízo que se forma antes, ou seja, indícios que se desvelam no ato de compreender. Conforme Gadamer (2002, p. 407), "“preconceito' não significa pois, de modo algum, falso juízo, pois está em seu conceito que ele possa ser valorizado positivamente ou negativamente". Nosso horizonte interpretativo está limitado à historicidade que nos cerca e ao caráter da experiência reflexiva. Mas, na medida em que vamos entrando em contato com outros meios, experimentando diferentes trajetórias compreensivas com capacidade de crítica, esse horizonte é ampliado. Para Gadamer, o meio nos oferece um horizonte de sentido prévio, de modo que o ponto de partida da compreensão nunca é neutro, pois já está inscrito em nossas précompreensões. Na medida em que nos abrimos ao diálogo com o diferente, possibilitamos o avanço interpretativo.

A compreensão implica sempre uma pré-compreensão que, por sua vez, é prefigurada por uma tradição determinada em que vive o intérprete e que modela os seus preconceitos. Assim, todo encontro significa a "suspensão" de meus preconceitos, seja o encontro com uma pessoa com quem aprendo a minha natureza e os meus limites, seja com uma obra de arte ("não há um lugar em que não possa ver-te, deves mudar a tua vida") ou com um texto; e é impossível contentar-se em "compreender o outro", buscar e reconhecer a coerência imanente aos significados-exigências do outro. (GADAMER, 2003, p. 13).

Partindo de nossos pressupostos e limites, deparamo-nos com um processo de espiral hermenêutico voltado à compreensão, ou como Gadamer denominou, com o círculo hermenêutico. $\mathrm{Na}$ interação, no diálogo e na abertura ao que o outro nos fala, em circunstâncias históricas momentâneas, estamos gerando sempre novas compreensões. No caso de um texto, ele cobra do leitor sempre novos posicionamentos, pois está aberto a alcançar novos horizontes a partir de quem o interpreta e não se restringe ao próprio autor da mensagem. Para Gadamer (2005, p. 407), "nossas reflexões sempre nos levaram a admitir que, na compreensão, sempre ocorre algo como uma aplicação do texto a ser compreendido à situação atual do intérprete”. Afinal de contas, não há compreensão humana que não seja mediatizada por linguagens, signos, símbolos e textos. Por isso, para que a compreensão ocorra é preciso que aquilo que tentamos interpretar faça sentido para nós mesmos. Gadamer (2005, p. 407) propõe como o problema da hermenêutica o tripé: interpretaçãocompreensão-aplicação, considerando a aplicabilidade "integrante do processo assim como a compreensão e a interpretação". Na perspectiva de Gadamer (2005, p. 29), 
[...] o fenômeno da compreensão e a maneira correta de se interpretar o compreendido não é apenas um problema específico da teoria aplicado às ciências do espírito. Desde os tempos mais antigos, sempre houve uma hermenêutica teológica e outra jurídica, cujo caráter não era teórico-científico, mas correspondia e servia muito mais ao procedimento prático do juiz ou do sacerdote instruídos pela ciência.

A hermenêutica vê além do que está sendo afirmado logicamente e sustentado pelas ciências, trazendo à tona os contextos de fundo em que um saber científico é constituído, em termos de fenômenos, atitudes, comportamentos humanos, textos e palavras. Segundo Gadamer (2005, p. 407), "atualmente a hermenêutica é a teoria metodológica da investigação das ciências do espírito". O que há de verdadeiramente comum e consensual a todas as formas de hermenêutica, é que "o sentido que se deve compreender somente se concretiza e se completa na interpretação" (GADAMER, 2005, p. 436). Em um incessante e inesgotável movimento circular, a compreensão vai sendo (re)construída. Assim, é na dinâmica de que só compreendemos a parte se compreendermos o todo, e só compreendemos o todo se compreendermos a parte, que se retroalimenta o círculo hermenêutico. O círculo é por natureza um processo de diálogo, e sendo a linguagem a essência da existência do Dasein, é notório que o horizonte de compreensões vai ampliando-se na medida em que a pré-compreensão é confrontada com outras posições, contradições e estranhamentos. A comunicação com o diferente possibilita que o círculo, em espiral hermenêutico, revele-se como inesgotável, já que a cada momento histórico as pré-compreensões são diferentes.

Se não houver uma postura de questionamento, no sentido de manter-se em constante autocrítica científica, e interesse dialógico ao outro, na busca de uma visão de conjunto, permitindo a ruptura dos preconceitos, não há interpretação. Portanto, o diálogo e a abertura ao outro, ao novo e ao diverso revelam-se primordiais. A arte de perguntar é, ao mesmo tempo, a arte de continuar perguntando, tornando-se a função da hermenêutica enquanto possibilidade de entrar em diálogo com o texto, pois "a capacidade para o diálogo é um atributo natural do homem" (GADAMER, 2005, p. 243). Conforme Gadamer (2005, p. 46),

Para que um diálogo aconteça, tudo precisa se afinar. Quando o companheiro de diálogo não nos acompanha e não vai além de sua resposta, mas só tem em vista, por exemplo, com que meios de contra-argumentação ele pode limitar o que foi dito ou mesmo com que argumentações lógicas ele pode estabelecer a refutação, não há diálogo algum - um diálogo frutífero é um diálogo no qual oferecer e acolher, acolher e oferecer conduzem, por fim, a algo que se mostra como um sítio comum com o qual estamos familiarizados e no qual podemos movimentar uns com os outros. 
Sendo assim, no diálogo atrelado as nossas circunstâncias históricas ocorre a mutabilidade da compreensão e o perecimento da pré-compreensão, uma vez que a cada contado com o outro (sujeito/objeto) a ser interpretado surgem novas compreensões e o horizonte de compreensão é alargado. Neste círculo, a hermenêutica entra como possibilidade de abertura e de mutabilidade da interpretação e de formação, para que os sujeitos possam refletir criteriosamente sobre os posicionamentos e resultados científicos, de modo a encontrarem-se capacitados em distinguir as estreitezas de interesses particulares e uma visão de conjunto. A experiência hermenêutica é a possibilidade de evoluir aprendizagens, de ser mais, de aprender com os outros sujeitos enquanto participantes de uma diversidade cultural. Subjacente ao processo interpretativo e compreensivo, que possibilita o círculo hermenêutico, está uma intencionalidade emancipatória de refletir sobre a práxis e aclarar as limitações, restrições, incoerências e preconceitos. Por isso, é sabido que o círculo hermenêutico é um círculo de possibilidades, já que a cada intencionalidade aplicada sob o objeto, gerará novas compreensões. A hermenêutica, enquanto recriadora de novos entendimentos sobre o mundo possibilita a participação do sujeito na construção do objeto e vice-versa. É nesse impasse dialógico que se delineia o círculo hermenêutico. Portanto, é factível que a compreensão está no diálogo, habita na linguagem, fruto do círculo hermenêutico, que ocorre no processo interpretativo diário. Partindo das próprias limitações históricas, inacabamentos e dos preconceitos, o sujeito revela-se um ser de possibilidades, já que pelo círculo hermenêutico os horizontes são ampliados num constante projetar-se.

\section{O CÍRCULO DE CULTURA É GERADO NO DIÁLOGO}

Paulo Freire é considerado um dos pensadores mais notáveis da educação, pois dedicou grande parte de sua vida ao reconhecimento do valor da educação para uma sociedade emancipada, bem como no combate às formas de pedagogia bancária, excludente e elitista. A educação se tornou, aos seus olhos, um instrumento de libertação e emancipação dos povos, das gentes. Suas reflexões tiveram incidência na sociedade brasileira na época de transição para a modernização, onde as disputas pelo poder político estavam centradas em duas grandes forças: urbano-industrial e agro-comercial. Estas foram as bases de 1955 a 1965 que propunham uma ideologia da consciência nacional, sugerindo o desenvolvimento do país. Paulo Freire expôs que é necessário aumentar o grau de atuação política da massa sobre as questões que estão ocorrendo na vida em sociedade, para o desenvolvimento de um discurso crítico necessário à interpretação da realidade e para a participação na vida pública. Freire acreditava que a libertação do sujeito oprimido seria possível por meio de uma educação problematizadora da realidade, alicerçada em perguntas provocadoras de 
inquietações e diálogos críticos na tomada de posição linguística sobre a vida coletiva. Para isso, sugeriu como potencial para uma pedagogia da autonomia o círculo de cultura, pois em cada corpo social existem temas geradores para serem discutidos, destacando-se a compreensão pela leitura crítica do passado, não como simples repetição, mas como participação num sentido presente, alargando horizontes de conhecimento do período histórico e do contexto social. Ou seja, para Freire compreender é participar num sentido, numa tradição, numa conversa, fazendo com que a nossa realidade seja enriquecida com novas compreensões encontradas na linguagem e na capacidade de agir no mundo.

Os círculos de cultura foram criados por Freire (1987) no final da década de 50 como uma forma de trabalhar o processo de aprender a partir da participação do aluno como sujeito de sua cultura, detentor de um saber gerado na prática social, que precisava ser problematizado pelos educadores e acrescentado a temas de dobradiça, a fim de ampliar o diálogo entre os sujeitos que também atuam, pensam e falam. (CONTE, 2012, p. 118).

De acordo com Freire, o diálogo é a autoridade epistêmica, e “investigar o 'tema gerador' é investigar, repitamos, o pensar dos homens referido à realidade, é investigar seu atuar sobre a ealidade, que é sua práxis" (FREIRE, 1982, p. 115). Os círculos de cultura são construídos nas relações, nas rodas de conversa, sem necessitar de um tema gerador para que o círculo se efetive nos grupos, uma vez que todos estão conectados a uma determinada realidade e a uma certa compreensão de mundo. A interpretação conjunta é gerada por meio de "um esforço comum da consciência da realidade e, autoconsciência, que a inscreve como ponto de partida do processo educativo, ou da ação cultural de caráter libertador" (FREIRE, 1982, p. 117). Os temas de debate geralmente eram propostos em consonância com o pensar a realidade e as necessidades da população, fazendo brotar investigações com os grupos no seio da linguagem e das relações pessoais locais, vistos na época como projetos inovadores de formação. Para a pesquisa dos temas geradores eram realizadas conversas informais com os moradores da localidade, em que "dirão o porquê, e como e o para que da investigação que pretendem realizar e que não podem fazê-lo se não se estabelece uma relação de simpatia e confiança mútuas" (FREIRE, 1982, p. 121). Os pesquisadores em seus diálogos com a população acionam um olhar crítico no local investigado, recolhendo subsídios para a compreensão dos modos de vida, de ser e de pensar dos sujeitos, a fim de que juntos possam tecer a sua descodificação, através de uma visão crítica e observadora da própria realidade.

Esta descodificação ao vivo implica, necessariamente, em que os investigadores, em sua fase, surpreendam a área em momentos distintos. É preciso que a visitem em horas 
de trabalho no campo; que assistam a reuniões de alguma associação popular, observando o procedimento de seus participantes, a linguagem usada, as relações entre diretoria e sócios; o papel que desempenham as mulheres, os jovens. É indispensável a visitem em horas de lazer; que conversem com pessoas em suas casas, registrando manifestações em torno das relações marido-mulher, pais-filhos; afinal, que nenhuma atividade, nesta etapa, se perca para esta compreensão primeira da área. (FREIRE, 1982, p. 124).

A partir de cada observação e registros, os pesquisadores produzem relatórios, que serão debatidos com todo o grupo de trabalho, tornando-se seminários (auto)avaliativos, e fazendo emergir o segundo momento da decodificação.

Com efeito, na medida em que, um a um, vão todos expondo como perceberam e sentiram este ou aquele momento que mais os impressionou, no ensaio "descodificador", cada exposição particular, desafiando a todos como descodificadores da mesma realidade, vai re-presentificando-lhes a realidade recém presentificada à sua consciência intencionada a ela. Neste momento, "re-admiram" sua admiração anterior no relato da "ad-miração" dos demais. (FREIRE, 1982, p. 124).

O propósito basilar dessa etapa é examinar a compreensão e as contradições dos sujeitos em questão, para a construção do conteúdo sensível às diferenças e ambiguidades para a ação educativa. De acordo com Freire (1982, p. 126), “esta visão é deles ainda, e não a dos indivíduos em face de sua realidade". A partir disso, inicia-se a fase em que os investigadores observam as inquietudes do conjunto, escolhendo determinadas situações ou contradições, a fim de serem codificadas pelo grupo.

$\mathrm{Na}$ medida em que representam situações existenciais, as codificações devem ser simples na sua complexidade e oferecer possibilidades plurais de análises na sua descodificação, o que evita o dirigismo massificador da codificação propagandística. As codificações não são slogans, são objetos cognoscíveis, desafios sobre o que deve incidir a reflexão crítica dos sujeitos descodificadores. As codificações, de um lado, são as mediações entre o "contexto concreto ou real", em que se dão os fatores e o "contexto teórico", em que são analisadas; de outro, são o objeto cognoscível sobre que o educador-educando e os educando-educadores, como sujeitos cognoscentes, incidem sua reflexão crítica. (FREIRE, 1982, p. 128).

Neste percurso, à medida que os investigadores trabalham com as decodificações, mais temas geradores surgem, com novos desdobramentos. Elaborada as codificações, os investigadores iniciam a terceira fase com a descodificação da produção coletiva. "Nesta, voltam à área para 
inaugurar os diálogos descodificadores, nos "círculos de investigação temática"” ou "círculos de cultura" (FREIRE, 1982, p. 131). Freire assinala a relevância da participação não apenas de educadores, mas também de todos os envolvidos nas relações educativas, para que a partir de suas capacidades específicas, colaborem com o processo de descodificação.

A estas reuniões de descodificação nos "círculos de investigação temática", além do investigador como coordenador auxiliar da descodificação, assistirão mais dois especialistas - um psicólogo e um sociólogo - cuja tarefa é registrar as reações mais significativas ou aparentemente pouco significativas dos sujeitos descodificadores. No processo de descodificação, cabe ao investigador, auxiliar desta, não apenas ouvir os indivíduos, mas desafiá-los cada vez mais, problematizando, de um lado, a situação existencial codificada e, de outro, as próprias respostas que vão dando àqueles no decorrer do diálogo. (FREIRE, 1982, p. 132).

Em seguida, "quando os investigadores, terminadas as decodificações nos círculos, dão início ao estudo sistemático e interdisciplinar de seus achados”, analisando as descodificações, os comentários elaborados pelos demais profissionais envolvidos nos círculos de investigação (FREIRE, 1982, p. 134). Neste momento, os temas são formados e distribuídos conforme um quadro geral de ciências, não representado uma desintegração do conhecimento investigado. Conforme Freire (1982, p.135), trata-se da necessidade de uma divisão mais característica de um tema, isto é, "feita a delimitação temática, caberá a cada especialista, dentro de seu campo, apresentar à equipe interdisciplinar o projeto de 'redução' de seu tema”. Esse processo de redução é de grande relevância, pois o especialista busca apenas o básico, sem deixar de dedicar um enfoque geral ao tema em questão.

Na discussão de cada projeto específico, se vão anotando as sugestões dos vários especialistas. Estas, ora se incorporam à "redução" em elaboração, ora constarão dos pequenos ensaios escritos sobre o tema "reduzido", ora uma coisa e outra. Estes pequenos ensaios, a que se juntam sugestões bibliográficas, são subsídios valiosos para a formação dos educadores-educandos que trabalharão nos "círculos de cultura". (FREIRE, 1982, p. 136).

No decurso da redução da temática, a população pode sugerir os temas mais significativos para a pesquisa, bem como a equipe precisa destacar os elementos mais importantes que não foram sugeridos pela população durante a investigação. Freire chamou isso de temas dobradiça, ou seja, a inserção de novos temas, consequência do modo dinâmico e relacional de ver a educação, uma vez que ela é dialógica. Freire (1982, p. 136) diz que, “como tais facilitam a compreensão entre dois temas no conjunto da unidade programática, contendo em si, as relações a serem percebidas entre o 
conteúdo geral e a visão de mundo que esteja tendo o povo". Após a realização do debate, o grupo de investigadores descreve um relatório para ser entregue ao especialista, destacando a reação da população sobre suas palavras, oportunizando uma troca de experiências entre a realidade local e os conhecimentos acadêmicos, encontrando aí pontos de diálogo. Freire dá a sugestão de que os temas sejam apresentados à população através de pequenas dramatizações, não precisando de respostas elaboradas, mas funcionando como uma espécie de codificação de uma realidade concreta, acompanhada de discussões e decodificação. Conforme Habermas (2009, p. 67), "uma língua não é propriedade privada de um indivíduo, mas cria um contexto de sentido intersubjetivamente partilhado, corporificado em expressões culturais e práticas sociais". Esse trabalho requer do sujeito abertura à alteridade e às múltiplas formas de aprender, em meio às mudanças da educação, uma vez que a construção do saber só estará consolidada pela leitura e reflexão crítica da realidade, que constitui o processo comunicativo.

Nesse processo de entendimento os sujeitos, ao atuar comunicativamente, se movem no meio da linguagem natural, se servem de interpretações transmitidas culturalmente e fazem referência simultaneamente a algo no mundo objetivo, no mundo social que compartilham e cada um a algo em seu próprio mundo subjetivo. (HABERMAS, 1987, p. 499-500).

A intersubjetividade é, portanto, o ponto de partida para a constituição do sujeito (falante e participante) e o elemento indispensável na tessitura da vida social, que conecta os sujeitos em uma racionalidade comunicativa processual e global de aprendizagens coletivas. A premissa na educação libertadora, conforme Freire (1982, p. 141), é que os estudantes se "sintam sujeitos de seu pensar, discutindo o seu pensar, sua própria visão de mundo, manifestada implícita ou explicitamente, nas suas sugestões e nas de seus companheiros". Isso só se torna possível por meio de uma cultura do diálogo aberto, sem absolutização de respostas ou perguntas, pois o dizer do mundo implica recriação constante de si na relação com o outro. "Se alguém não é capaz de sentir-se e saber-se tão homem quanto os outros, é que lhe falta ainda muito que caminhar para chegar ao lugar de encontro com eles" (FREIRE, 2005, p. 93). Nos espaços de encontro, nos círculos de cultura ou no quintal dialógico, "não há ignorantes absolutos, nem sábios absolutos: há homens que, em comunhão, buscam saber mais" (FREIRE, 2005, p. 95). Freire observa que a capacidade de diálogo é a abertura à inquietação e à curiosidade epistemológica de aprender e evoluir com o outro, indo além da uniformização ou homogeneização das consciências de forma alienadora. "Porque os sujeitos dialógicos não apenas conservam sua identidade, mas a defendem e assim crescem uns com os 
outros. O diálogo, por isso mesmo, não nivela, não reduz um ao outro. Nem é favor que um faz ao outro" (FREIRE, 2006, p. 118).

Assim, o círculo de cultura constitui-se numa educação libertadora, inexistindo lugares demarcados ou reservados para aqueles que tudo sabem, ao contrário, reclamam a participação ativa de todos para iniciar novos debates e diálogos em busca de uma reflexão mais profunda para o reconhecimento de si e do mundo. Freire projetava na alfabetização dos sujeitos por meio dos círculos de cultura, afastamentos a uma educação mecânica, abstrata e descontextualizada, no sentido de direcionar os sujeitos para a tomada de consciência crítica da realidade, com a finalidade de politizar a cultura popular. Nesse sentido, o sujeito não age sozinho no mundo, mas interage com os outros, socializando ideias, tecendo relações com o meio social e projetos de vida na construção de novas reflexões, diálogos, aprendizagens e pondo o conhecimento em debate por meio dos círculos de cultura. Freire (2011,p. 47) afirma que:

O educando se reconhece conhecendo os objetos, descobrindo que é capaz de conhecer, assistindo a imersão dos significados em cujo processo se vai tornando também significador crítico. Mais do que ser educando por causa de uma razão qualquer, o educando precisa tornar-se educando como sujeito cognoscente e não como incidência do discurso do educador.

Fazendo uma analogia com o círculo hermenêutico que pode ser compreendido pela linguagem, desde a experiência da alteridade, instala-se o círculo da compreensão com seus alcances educacionais. "[...] Pode-se dizer que o círculo de cultura visa o entendimento, a partir da problematização de diferentes leituras da realidade, e compõe-se de mecanismos de coordenação das ações, mediante os quais se estabelecem as relações interpessoais e se exercem diferentes práxis no mundo" (CONTE, 2012, p. 119).

\section{CONSIDERAÇÕES FINAIS}

Nos conceitos de Gadamer e Freire há uma forte similitude na linguagem como capacidade de agir e compartilhar conhecimentos em círculos de cultura, numa mesma marcha pela emancipação coletiva. No círculo hermenêutico nos é apresentado o sujeito como portador de uma pré-compreensão, daquilo que o torna interpretante, uma vez que esse é socialmente e historicamente condicionado. Por isso, a compreensão pela leitura não é a simples repetição de algo passado, mas participação num sentido presente, alargando nossos horizontes de conhecimento e enriquecendo nossa realidade com novas compreensões. Também, no círculo de cultura, notamos que a emancipação se dá no coletivo e deve partir do próprio contexto, já que estamos inseridos no 
mundo. Ancorados na linguagem, que Gadamer e Freire justificam suas abordagens, que podem ser traduzidas em alianças dialógicas e culturais para uma educação emancipatória. Sem dúvida, compartilham da ideia de que é no encontro diálogo com o diverso, com o diferente, que ocorre a ampliação de nossos próprios horizontes de mundo. Tanto Gadamer quanto Freire observam que a capacidade de diálogo é a abertura às inquietações e à curiosidade epistemológica de aprender e evoluir com o outro. Se somos sujeitos de possibilidades no mundo, para além da uniformização ou homogeneização de formas alienadoras, é porque temos a oportunidade de aprender cooperativamente e de pronunciar o mundo no processo interpretativo e renovado de compreensões.

Tendo em vista questões emergentes, os círculos renovam e atualizam as nossas visões de mundo na fusão de horizontes da própria autoexposição virtual e na interdependência em que percebemos as formas discursivas, buscando a compreensão crítica e ativa dos sujeitos sobre o conhecimento. Tais conceitos explorados nas experiências atuais possibilitam o diálogo, na medida em que os participantes expõem seus preconceitos sobre o assunto em pauta (seja virtual ou presencial), influenciando uns aos outros com seus comentários e mensagens, o que permite que as opiniões subjetivas mudem ou sejam revistas ao longo do processo. Portanto, o diálogo é o horizonte de análise da prática social tanto no círculo hermenêutico de Gadamer, quanto no círculo de cultura de Freire. É no encontro e no conflito com o diferente que os preconceitos e as estruturas alienantes são rompidas, tornando compreensíveis estruturas da pluralidade presentes na linguagem, para aprimorar e reconhecer a reflexividade como condição para aprender coletivamente e emancipar-se.

\section{REFERÊNCIAS}

CONTE, Elaine. Aporias da performance na educação. Tese (Doutorado). Universidade Federal do Rio Grande do Sul. Faculdade de Educação - PPGEDU. Porto Alegre, 2012. 283f.

FREIRE, Paulo. Pedagogia do oprimido. 11. ed. Rio de Janeiro: Paz e Terra, 1982.

Extensão ou Comunicação? 11. ed. Rio de Janeiro, Paz e Terra, 2006.

Educação como prática da liberdade. 34. ed. São Paulo: Paz e Terra, 2011.

GADAMER, Hans-Georg.; FRUCHON, Pierre (Org.). O problema da consciência histórica. 2. ed. Trad. Paulo César Duque Estrada. Rio de Janeiro: FGV, 2003.

GADAMER, Hans-Georg. Verdade e método. 7. ed. Trad. Flávio Paulo Meurer (revisão da tradução de Enio Paulo Giachini). Petrópolis: Vozes, Bragança Paulista: EDUSF, 2005.

HABERMAS, Jürgen. Dialética e Hermenêutica. Porto Alegre: L\&PM, 1987.

2009.

Verdade e Justificação - ensaios filosóficos. 2. ed. Trad. Milton Camargo Mota. São Paulo: Edições Loyola,

MISSAGGIA, Juliana. A hermenêutica em Heidegger e Gadamer: algumas confluências e divergências. Griot Revista de Filosofia, Amargosa, Bahia, Brasil, v.6, n.2, dez. 2012. 


\section{RESUMO}

O texto versa sobre o círculo hermenêutico de Gadamer e o círculo de cultura de Freire, buscando os encontros e as semelhanças desses pensadores no enlace dialógico. Tal ato impulsiona o enfrentamento necessário para qualquer ato de compreensão das questões humanas, uma vez que a ampliação de horizontes linguísticos se revela de múltiplas faces, sendo impossível ter a última palavra. Nos impasses e aporias dialógicas são construídas as intercompreensões numa espiral hermenêutico-reflexiva. Para Freire, o círculo de cultura surge como possibilidade de superação da opressão em que vive o oprimido, cuja libertação será através do diálogo, um espaço em que todos têm a palavra, possibilitando interpretar o mundo constantemente. Concluímos que em ambas as perspectivas, torna-se necessário o diálogo vivo com o outro, que ativa infindáveis interpretações, pois para aprender e aprimorar a reflexão é preciso reconhecer e tornar compreensíveis estruturas da pluralidade humana.

Palavras-chave: Círculo hermenêutico. Círculo de cultura. Diálogos.

\section{PROSPECTING IDEAS FOR THE RECONSTRUCTION OF THE HERMENEUTIC CIRCLE AND THE CIRCLE OF CULTURE}

\section{ABSTRACT}

The text is about the hermeneutic circle of Gadamer and Freire's circle of culture, looking for the common points and the similarities of those thinkers in the dialogical link. Such an act drives the necessary confrontation for any act of understanding human questions, since the enlargement of linguistic horizons reveals itself with multiple faces, where is impossible to have the last word. In the impasses and dialogical aporias are built the intercomprehensions in a hermeneutic-reflexive spiral. For Freire, the circle of culture comes as a possibility of overcoming the oppression in which the oppressed lives, whose liberation will be through dialogue, a space in which everyone has the word, making it possible to interpret the world constantly. So, we conclude that in both perspectives it becomes necessary to have a living dialogue with the other, which activates endless interpretations, since to learn and to improve reflection one must recognize and make understandable structures of human plurality.

Keywords: Hermeneutic circle. Circle of culture. Dialogues.

\section{GARIMPANDO IDEAS PARA LA RECONSTRUCCIÓN DE LO CÍRCULO HERMENÉUTICO Y DE LO CÍRCULO DE CULTURA}

\section{RESUMEN}

Este artículo trata sobre el círculo hermenéutico de Gadamer y el círculo de cultura de Freire, en busca de las reuniones y las similitudes de estos pensadores en el enlace dialógica. Tal acto impulsa la confrontación necesaria para cualquier acto de comprensión de los asuntos humanos, ya que la extensión de los horizontes linguísticos revela varias caras, por lo que es imposible tener la última palabra. En los separadores se construyen y dialógica aporías los intercompreensões una espiral hermenéutica-reflectante. Para Freire, el círculo de cultura aparece como una posibilidad para superar la opresión en que viven los oprimidos, cuya liberación será a través del diálogo, un espacio de tomada de posición en que todo el mundo tiene la palabra, por lo que es posible interpretar el mundo constantemente. Concluimos que en ambas perspectivas, se hace necesario el diálogo vivo con el otro, que activa interminables interpretaciones, pues para aprender y perfeccionar la reflexión hay que reconocer y hacer comprensibles estructuras de la pluralidad humana.

Palabras-clave: Círculo hermenéutico. Círculo de cultura. Diálogos. 